\title{
METODE DESAIN DARI BRAND MENJADI MASKOT BERDASARKAN ADAPTASI METODE ALINA WHEELER KE DALAM MODEL 5M
}

\author{
Erik Armayuda', Reven Praga Deva ${ }^{2}$ \\ ${ }^{1}$ Desain Komunikasi Visual, Fakultas Industri Kreatif dan Telematika, Unviersitas Trilogi \\ ${ }^{2}$ Desain Komunikasi Visual, Fakultas Seni Rupa dan Desain, ITB \\ armayuda@trilogi.ac.id ${ }^{1}$, revendeva@gmail.com ${ }^{2}$
}

\begin{abstract}
Abstrak
Maskot memiliki peran penting dalam sebuah pendekatan emosional dari sebuah instansi, atau lembaga baik komersil maupun non komersil. Sebagai keilmuan yang mengakomodasi kajian perancangan maskot, terutama dalam proses pembelajaran, belum ada panduan baku proses perancangan maskot secara metodologis. Untuk itu diperlukan sebuah acuan baku yang bisa digunakan dalam proses perancangan maskot yang sistematis dan dapat dipertanggungjawabkan secara ilmiah. Paper ini bertujuan untuk memberikan satu alternatif metode perancangan yang runtut yang diformulasikan dari metode komparasi teori brand, dan perancangan karakter. Mengingat konteks maskot dan keilmuan desain komunikasi visual memiliki irisan dengan keilmuan marketing, maka paper ini juga mengacu pada rujukan strategis dalam perancangan sebuah brand oleh Alina Wheeler. Dengan mengadaptasi metode mendesain brand tersebut, penulis menerjemahkan setiap tahapnya dan mengadaptasi istilah di dalamnya dan menariknya ke dalam konteks perancangan maskot dengan fokus pembahasan ke dalam perumusan strategi visual. Untuk memberikan gambaran yang spesifik, penelitian ini juga memberikan studi kasus yang menunjukan tahapan penerapan model. Dari proses adaptasi tersebut maka dirumuskanlah model 5M; 1) Merumuskan kata kunci, 2) Merumuskan brief persona maskot 3) Merumuskan brief bentuk dan siluet, 4) Merumuskan gestur, 5) Merumuskan pengemasan media. Penulis berharap model $5 \mathrm{M}$ tersebut dapat dijadikan acuan dalam proses perancangan maskot khususnya dalam konteks pembelajaran desain.
\end{abstract}

Kata Kunci: 5M, Alina Wheeler, brand, maskot, metode

\begin{abstract}
The mascot has a significant role in an emotional approach from both commercial and noncommercial institutions. There are no official standard guidelines in the design process. For this reason, a standard reference is needed that can be used in the process that is systematic and scientifically justified. This paper aims to provide a coherent alternative design method formulated by the comparative method of brand theory and character design. Mascot and visual communication design science have a slice with marketing science, therefor this paper also refers to the design of a brand by Alina Wheeler. By adapting the brand design method, the writer translates each stage and adapts the terms and draws it into the context of the design of the mascot with the focus of discussion into the formulation of visual strategies. This research also provides the design stages of applying the model. From the adaptation process a $5 \mathrm{M}$ model was formulated; 1) Formulate keywords, 2) Formulate the mascot persona brief 3) Formulate the shape and silhouette briefs, 4) Formulate gestures, 5) Formulate media packaging. The author hopes that the $5 \mathrm{M}$ model can be used as a reference in the mascot design process, especially in the context of design learning.
\end{abstract}

Keywords: brand transformation, design methods, mascot design 


\section{PENDAHULUAN}

Kita hidup di zaman ketika merek (brand) menjadi salah satu keputusan terpenting dalam pengambilan keputusan pembelian. Merek pada dasarnya sangat lekat dengan disiplin ilmu marketing atau pemasaran, namun dalam ranah eksekusinya merek adalah bagian dari keilmuan desain, khususnya desain komunikasi visual. Ada lima langkah penting dalam mengembangkan merek yang baik: 1) melakukan penelitian, 2) memperjelas strategi, 3) merancang identitas, 4) Menciptakan titik sentuh, dan 5) mengelola aset (Wheeler, 2009: 90). Merek sejatinya adalah identitas non visual yang diikat oleh faktor-faktor visual. Merek menjadi satu identitas sebuah produk atau perusahaan yang memiliki irisan keilmuan desain dan marketing. Untuk itulah dalam konteks desain, merek menjadi studi keilmuan pada ranah visual. Surianto rustan dalam bukunya mendesain logo menyatakan bahwa jika logo adalah sebuah wajah, maka merek merupana badan sebuah perusahaan (Rustan, 2009: 13). Hal tersebut dikarenakan merek atau dalam istilah populernya brand mencakup segala aspek yang dapat dipertimbangkan sebagai sebuah kredibiltas perusahaan. Aspek-aspek tersebut bisa berupa pelayanan, hingga strategi pemasaran yang menimbulkan citra atau kesan pada konsumen yang cenderung bersifat emosional. Mengembangkan hubungan emosional dengan konsumen, pada dasarnya, mengembangkan hubungan dengan mereka (Mohanty, 2014: 42). Pada akhirnya semua upaya dalam merumuskan strategi penerimaan sebuah merek merupakan bagian dari strategi pemasaran yang diarahkan pada proses pengambilan keputusan saat membeli produk.

Jika merek adalah tubuh sebuah perusahaan dan logo adalah wajah yang berhadapan langsung dengan konsumen, maka maskot adalah elemen pemasaran yang bisa langsung menjabat konsumen dengan karakteristik emosionalnya. Maskot adalah tokoh karakteristik yang dapat membangun identitas dan membantu menciptakan dan mengekspresikan kepribadian merek. Mengembangkan hubungan emosional dengan konsumen, pada dasarnya, mengembangkan hubungan dengan mereka (Mohanty 2014). Maskot telah ditemukan sebagai cara yang paling penting dan relevan, murah dan terbaik untuk pemasaran produk (Kochhar \& Singh 2019). Studio Tubik dalam Ux planet mendeskripsikan maskot sebagai karakter, gambar yang dipersonifikasikan yang menjadi representasi simbolik dari merek, perusahaan, atau bahkan figur publik. Tidak semua perusahaan membutuhkan merek namun semua maskot biasanya merepresentasikan perusahaan, lembaga, bahkan kelompok komunitas tertentu sebagai upaya dalam mewujudkan sesuatu yang abstrak dalam bentuk yang kongkrit. Dalam konteks akademisi, khususnya dalam pembelajaran desain, telah banyak model dan metode untuk merumuskan perancangan logo yang baik, namun belum banyak yang mengulas bagaimana metode perancangan maskot yang komprehensif. Bahkan sebelum itu perancang maskot harus mengetahui seberapa urgent perancangan maskot diperlukan untuk perusahaan tersebut.

Penelitian ini akan memberikan panduan mulai dari analisis urgensi perancangan maskot, dampak yang ingin dicapai, perumusan identitas perusahaan dalam simbolsimbol, hingga panduan merumuskan bentuk, karakter, dan personalitas dari maskot yang akan dirancang sebagai bentuk kristalisasi identitas perusahaan. 


\section{METODE PENELITIAN}

Metode yang digunakan dalam penelitian untuk merumuskan model perancangan maskot ini adalah metode komparatif atau perbandingan. Sedangkan hal yang dibandingkan dalam penelitian ini dilakukan dengan menjadikan pemikiran tiga layer model desain kreatif budaya oleh Hsu, Lin, dan Chu, (2004) yang menjelaskan adanya layer dalam sebuah desain dengan menggabungkan pendapat Norman ke dalamnya. Norman (2002) sendiri dalam bukunya Emotional Design menjabarkan bahwa ada tiga level dalam desain, di antaranya level visceral, behavioral, dan reflective. Kominov (2020) dalam international foundation design menjabarkan ketiga level tersebut sebagai berikut: Level visceral adalah penekanan desain pada penampakanya. Level ini mempengaruhi penampilan sebuah desain pada kemampuan penggunanya mempersepsi kegunaan sebuah desain. Tindakan membedakan satu produk dari yang lain, bukan oleh manfaat nyata yang ditawarkan pengguna tetapi dengan memanfaatkan sikap, keyakinan, perasaan pengguna, dan bagaimana mereka ingin rasakan, sehingga memperoleh respons emosional semacamnya.

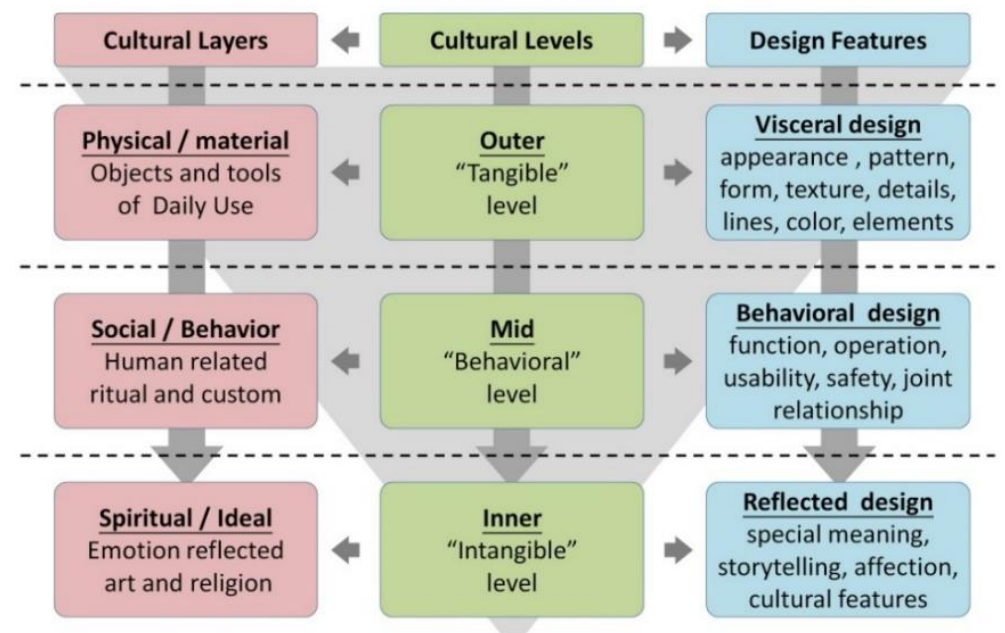

Gambar 1. Tiga Layers Model Desain Kreatif Budaya [Sumber: Hsu, Lin, \& Chu, 2004]

Level behavioral desain menjadi level yang paling mudah untuk diuji, karena tingkat kinerja dapat diukur setelah fisik (misal, Pegangan, tombol, pegangan, tuas, sakelar, dan kunci) atau bagian yang dapat digunakan dari suatu objek diubah atau dimanipulasi dengan cara tertentu. Seperti kasus dua tombol yang memiliki fungsi berbeda jika diletakkan pada sebuah jarak tertentu dapat di uji efektifitas penggunaanya. Sedangkan pada level reflectif, memediasi efek dari tingkat perilaku - pengguna mungkin menghadapi kesulitan dan kekurangan dalam kegunaan smartwatch karena mereka percaya mereka akan mendapatkan manfaat lain yang non-fungsional dari itu. Ketiga level tersebut berada dalam tataran emosional.

Melalui metode komparasi, jika direfleksikan dalam bentuk sebuah perusahaan dan kaitannya dengan desain dan pemasaran, ketiga level desain tersebut dapat ditarik menjadi logo, brand, dan maskot. Pada level vosceral, logo memberikan penekanan pada penampakan visual dan perepsi yang erat kaitanya dengan kaidah-kaidah sebuah 
tampilan desain dan persepsinya di mata konsumen. Pada level behavioral aspek-aspek kinerja yang non visual, keefektifan, strategi, dan kinerja diwakili oleh brand. Sedangkan pada level reflective maskot merupakan perumpaaan yang tepat mengingat maskot bisa memediasi ekspresi emosional sebuah merek. Instrumen maskot merek banyak digunakan dalam pemasaran modern karena efektivitas dan kemampuannya untuk menciptakan ikatan emosional dengan pelanggan (Yadav, 2017).
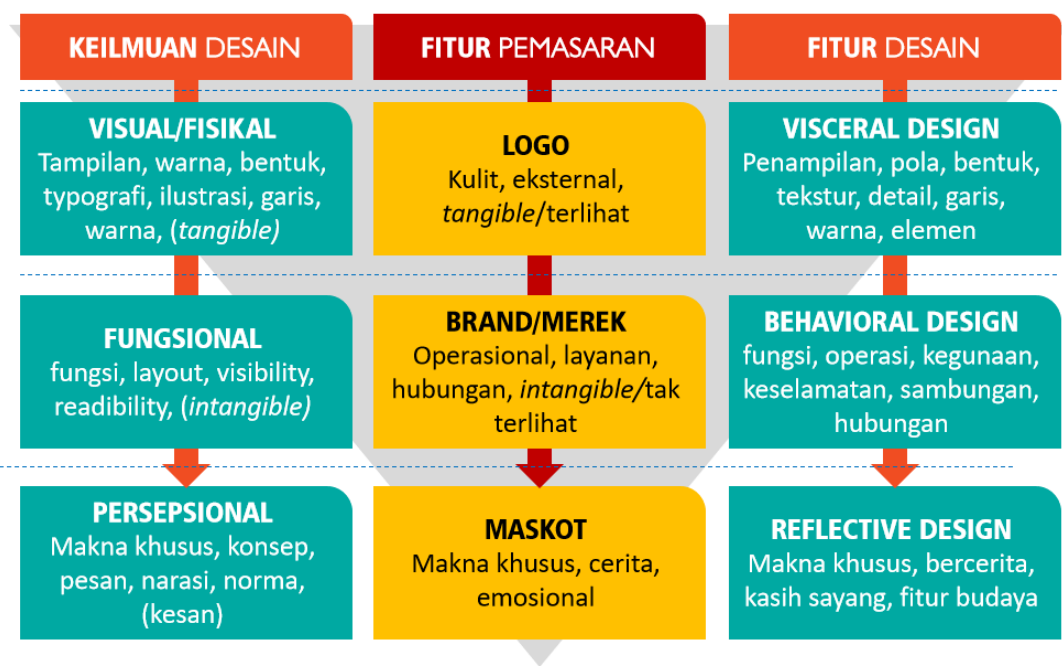

Gambar 2. Adaptasi tiga level desain ke dalam konteks maskot dan desain [Sumber: Armayuda, 2020]

\section{HASIL DAN PEMBAHASAN}

\subsection{Perbandingan Perancangan Brand}

Dalam tahapan perancangan sebuah Brand, Aline Wheeler membagi ke dalam 5 tahapan dengan petunjuk rincian teknis di setiap tahapanya; 1) melakukan penelitian, 2) memperjelas strategi, 3) merancang identitas, 4) Menciptakan titik sentuh, dan 5) mengelola aset (Wheleer 2009). Pada tahapan melakukan penelitian ia membagi ke dalam beberapa petunjuk teknis mulai dari memperjelas visi, strategi, tujuan, dan nilainilai, hingga melakukan audit, begitu juga ke empat tahapan selanjutnya sebagaimana yang dapat dilihat dari gambar 3 di bawah.

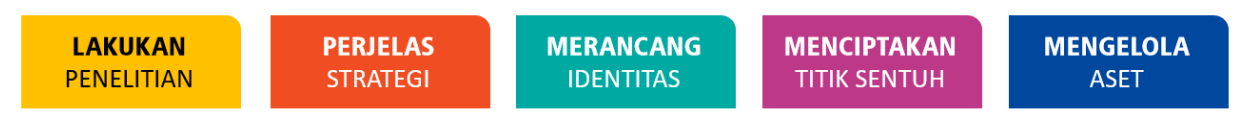

Gambar 3. Tahapan perancangan brand

[Sumber: Wheeler, 2009, p.6-7]

Secara teoritis model tersebut digunakan sebagai panduan umum perancangan sebuah brand perusahaan yang mencakup tangible dan intangible aset, atau aset yang tampak seperti logo perusahaan, warna, layanan dan aset yang tak tampak seperti nilai-nilai dalam perusahaan hingga strateginya dalam memenangkan persaingan. Mengingat dalam pembahasan ini penulis akan mengadaptasi model tersebut dalam konteks pembelajaran dalam keilmuan desain, maka secara garis besar penulis menyeleksi segala jenis rincian detail di setiap tahapanya hanya pada ranah yang relevan dengan 
proses sebuah desain. Lebih spesifik lagi penulis akan menyeleksi tahapan teknis hanya pada konteks yang berhubungan langsung dengan konteks perancangan maskot.

LAKUKAN
PENELITIAN
Perjelas visi, strategi,
tujuan, dan nilai-nilai.
Penelitian kebutuhan
pemangku
kepentingan dan
persepsi.
Melakukan pemasaran,
kompetitif, teknologi,
hukum, dan bahasa
audit.
Wawancara
manajemen kunci.
Mengevaluasi merek
yang ada dan
arsitektur merek.
Hadirkan pembacaan
audit.

\begin{tabular}{l}
\multicolumn{1}{c}{ PERJELAS } \\
STRATEGI \\
Mensintesis \\
pembelajaran. \\
Perjelas strategi merek. \\
Kembangkan posisi \\
platform. \\
Ciptakan atribut \\
merek. \\
Tulis briefing merek. \\
Mencapai kesepakatan. \\
Buat strategi \\
penamaan. \\
Kembangkan pesan- \\
pesan utama. \\
Tulis brief kreatif. \\
\end{tabular}

\section{MERANCANG IDENTITAS}

Visualisasikan masa depan.

Brainstorm ide besar. Desain identitas merek.

Jelajahi aplikasi.

Finalisasi arsitektur

merek.

Sajikan strategi visual. Mencapai kesepakatan.

\section{MENCIPTAKAN TITIK SENTUH}

Finalisasi desain identitas.

Kembangkan tampilan dan nuansa.

Lakukan perlindungan merek dagang. Prioritaskan dan desain aplikasi.

Program desain

Terapkan arsitektur merek

\section{MENGELOLA ASET}

Gambar 4. Detail tahapan perancangan brand [Sumber: Wheeler, 2009, p.6-7]

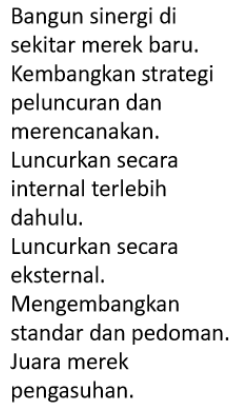

Sehingga dari proses seleksi tersebut didapatlah satu kelompok rincian aksi dalam setiap tahapan yang ditandai sebagaimana yang terlihat pada gambar 4 di bawah ini.

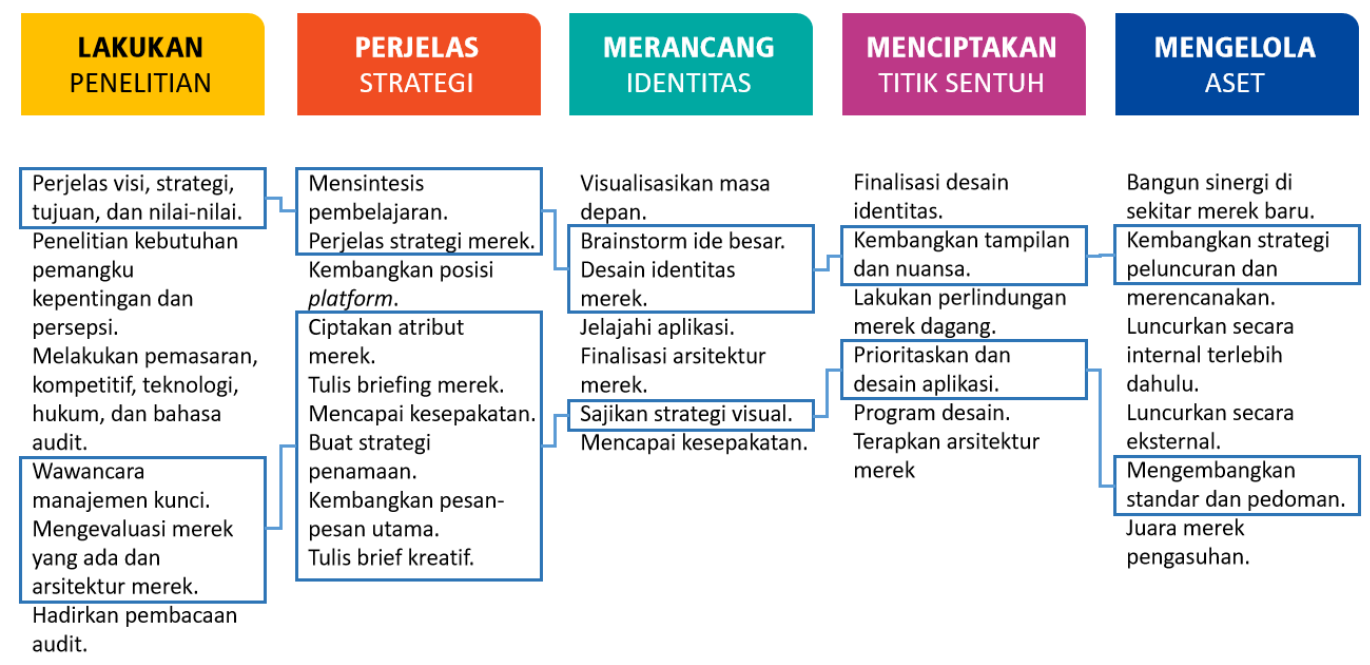

Gambar 5. Seleksi tahapan yang relevan dengan perancangan maskot

[Sumber: Armayuda, 2020]

Dari gambar di atas dapat diketahui bahwa pada tahapan yang relevan ditandai dengan kotak prioritas yang harus dilakukan dalam konteks desain. Secara spesifik tahapan tersebut dapat dijabarkan sebagai berikut. Dari perumusan tersebut bisa dirumuskan teknis tindakan yang harus dilakukan pada setiap tahapan adalah sebagai berikut:

1. Melakukan Penelitian. Pada tahap ini terdapat tiga hal utama yang relevan dan harus dilakukan dalam mencari data memperjelas visi, strategi, tujuan, dan nilai-nilai, melakukan wawancara untuk menemukan kunci, mengevaluasi merek yang telah ada dan arsitekturnya. 
2. Memperjelas Strategi. Tahapan ini memberikan gambaran bahwa langkah yang relevan adalah, mensintesis pembelajaran, memperjelas strategi, menciptakan atribut, menulis briefing, mencapai kesepakatan, membuat strategi penamaan, mengembangkan pesan utama, hingga merumuskan brief kreatif.

3. Merancang Identitas. Pada tahap ini tidak selain, brainstorm ide besar, mendesain identitas merek, dan strategi menyajikan secara visual.

4. Menciptakan Titik Sentuh. Di sini tahap relevansinya adalah, mengembangkan tampilan dan nuansa, memilih prioritas dan mendesain penerapanya.

5. Mengelola Aset. Tahapan ini berkaitan dengan pengelolaan aset, sehingga proses yang relevan dalam perancangan maskot adalah; mengembangkan strategi peluncuranya dan mengembangkan standar pedoman.

\subsection{Proses Adaptasi Perancangan Maskot}

Setelah tahapan penyeleksian sebagaimana yang telah dilakukan, maka pada tahap ini perumusan model dilakukan dengan cara meredefinisi setiap tahapan dan memfokuskan kembali rincian teknis tahapannya. Dari adaptasi tersebut dapat dirumuskan bahwa kelima tahapan dari; melakukan penelitian, memperjelas strategi, merancang identitas, menciptakan titik sentuh, dan mengelola aset dapat disintesiskan ke dalam lima tahapan merancang brand dengan istilah yang lebih relevan sebagai berikut; 1) Menganalisa urgensi dan semangat, 2) Mendefinisikan identitas, 3) Mensketsa bentuk, 4) Merumuskan karakter, dan 5) Menampilkan maskot, seperti yang dapat dilihat pada gambar di bawah ini.

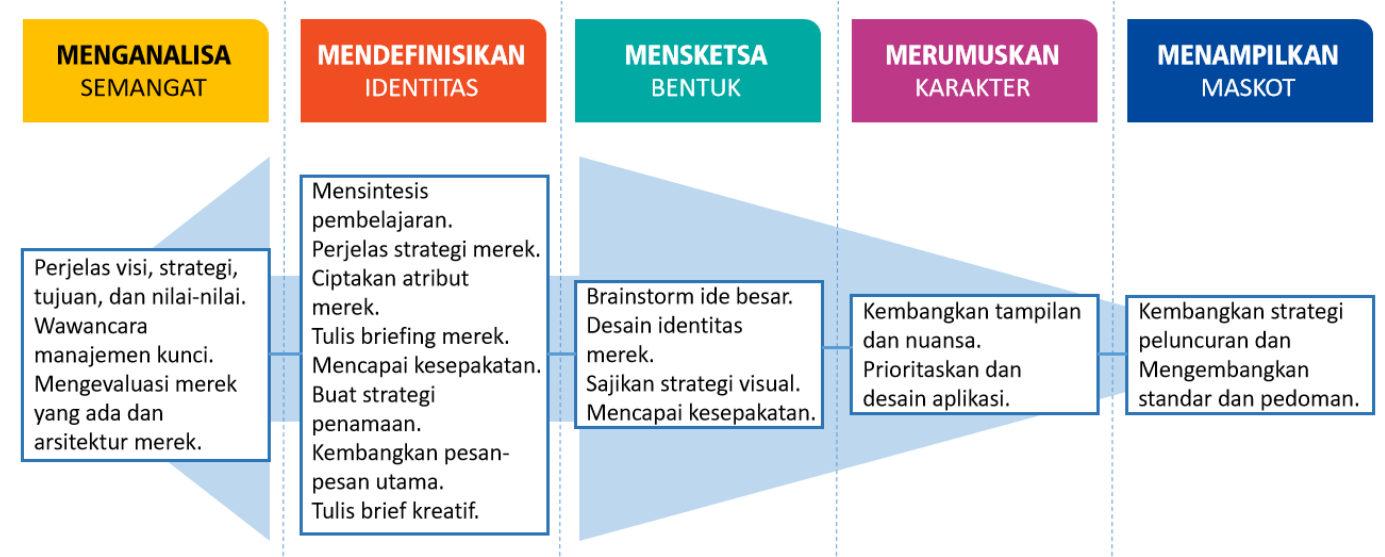

Gambar 6. Formulasi metode desain dalam merancang maskot

[Sumber: Armayuda, 2020]

Dari hasil sintesis istilah tahapan perumusan maskot dapat diketahui bahwa ada beberapa tahapan yang harus dilalui pertama kali adalah menganalisa urgensi perancangan maskot. Hal tersebut wajar dilakukan dikarenakan tidak semua perusahaan dan merek membutuhkan maskot, dan jika urgensi telah ditentukan maka perlu dirumuskan semangat perusahaan tersebut. Hal tersebutlah yang menjadikan tahapan teknisnya menjadi penting dengan menganalisa visi, misi, strategi, tujuan, dan nilai-nilai merek melalui wawancara diharapkan dapat merupuskan urgensi/semangat perancangan maskot berdasarkan arsitek merek itu sendiri. Jika tahapan ini telah dilakukan maka hal berikutnya menjadi penting jika urgensi perancangan maskot 
memang dibutuhkan dengan cara mendefinisikan identitas merek. Hal tersebut mencakup kelebihan merek dan bagaimana merek tersebut ingin dipresepsikan oleh pelanggan.

Dalam menentukan brief juga harus dipertimbangkan fungsi dari karakter maskot tersebut nantinya, sebagaimana yang disampaikan Armayuda (2016), bahwa ada dua fungsi karakter, fungsi stationary. Fungsi stationary bertujuan memperkuat branding satu produk atau perusahaan. Sedangkan fungsi story dibangun berdasarkan cerita tertentu. Maskot bisa direfleksikan ke dalam salah satu dari dua hal tersebut.

Dari karakter yang telah ditetapkan itu baru bisa memasuki tahapan lanjutan berupa proses sketsa bentuk. Agar proses lebih detail dan relevan mensketsa bentuk sebaiknya dimulai dari sisi siluet dan gestur sebelum didetailkan ke ranah tampilan dan detail elemen visual lainya. Bagaimana merek tersebut akan disajikan dan apa ide besarnya. Hal ini sejalan dengan proses desain Scott Roger (2010) yang menyatakan bahwa proses mendesain karakter dapat didasarkan dengan bentuk bidang dasar. Lingkaran merepresentasikan karakter yang bersahabat, kesan kuat atau bodoh bisa diambil dari bentuk kotak. Sedangkan segitiga mengikuti posisinya, jika menghadap ke bawah biasa menjadi sosok superhero yang kuat, sedangkan jika digunakan sebagai kepala, bisa memberi kesan jahat.

Setelah tahapan sketsa bentuk, tahap berikutnya adalah mengisi bentuk itu dengan mengembangkan nuansa tampilanya di ranah visual yang lebih detail berupa ekspresi tampilan (cara berdiri dan berpose) dan gestur yang ingin ditampilkan. Pada tahap terakhir adalah tahap presentasi maskot dengan media-media yang relevan dalam mendukung citra maskot tersebut.

Dari semua proses di atas dapat disimpulkan pada poin kunci perancangan maskot mulai dari; 1) Merumuskan kata kunci: dan mengevaluasi urgensi perancanganya, 2) Merumuskan brief karakter yang tak terlihat: seperti sifat, gimik, arketip, dan sejenisnya, 3) Merumuskan brief yang terlihat: sebatas bentuk siluet maupun analogi bentuk (dalam beberapa kasus maskot mengambil bentuk yang telah ada seperti hewan dan tumbuhan), 4) Merumuskan gestur: mood, warna, gestur, dan nuansa karakter di dalam siluet pada tahap sebelumnya, 5) Merumuskan pengemasan media: dan aturan baku mengenai peng-implementasianya.

\subsection{Hasil Adaptasi Perancangan Brand ke dalam Perancangan Maskot}

Berdasarkan model perancangan di atas dapat dijabarkan secara detail metode perancangan maskot dari adaptasi proses mendesain brand Alina Wheeler adalah dengan merumuskan beberapa poin penting sebagai berikut: 1) kata kunci, 2) brief sifat/personalitas karakter, 3) brief bentuk siluet, 4) nuansa karakter, dan 5) implementasianya. Secara lebih detail tahapan di atas dapat dijabarkan sebagai berikut:

1. Merumuskan kata kunci: Tahapan ini dimulai dengan mngevaluasi urgensi perancangan maskot, Jika sudah ditentukan urgensinya maka desainer hendaknya mempelajari visi, misi, strategi, merek/perusahaan terkait untuk dirumuskan ke 
dalam beberapa kata kunci yang akan menjadi acuan brief implementasi tahapan selanjutnya.

2. Merumuskan brief karakter: Tahap ini dilakukan dengan cara mensintesis kata kunci visi, misi, dan strategi ke dalam karakter personal atau dalam istilah sederhana adalah personifikasi karakter dari kata kunci perusahaan.

3. Merumuskan bentuk: Tahap ini adalah tahap di mana personifikasi pada tahap sebelumnya diwujudkan dalam wujud sketsa bentuk. Dalam membuat sketsa bentuk ini bisa didasarkan pada analogi personifikasi pada bentuk yang sudah ada berdasarkan kaidah filosofisnya seperti sifat-sifat binatang, dan tumbuhan.

4. Merumuskan nuansa karakter: Merupakan tahap di mana bentuk yang telah disepakati diolah kedalam draft sketsa yang lebih detail dengan menambahkan atribut gestur, ekspresi tampilan, dan elemen-elemen pendukung lainya.

5. Merumuskan panduan implementasi: Pada tahap ini menjadi tahapan yang paling penting. Meskipun maskot telah jadi pada tahap sebelumnya namun tahap ini akan menentukan bagaimana maskot tersebut akan dipresepsikan, mengingat pada tahap ini adalah panduan pengimplementasian yang berhubungan dengan penempatan, implementasi media, dan konteks-konteks lainya yang harus diperhatikan untuk memperkuat kesan bukan malah menjatuhkan kesan yang sedang ingin dibangun.

Kelima proses di atas untuk lebih mudah diingat selanjutnya dapat disebut dengan model 5M (Merumuskan, kata kunci, brief, bentuk, nuansa, dan panduan).

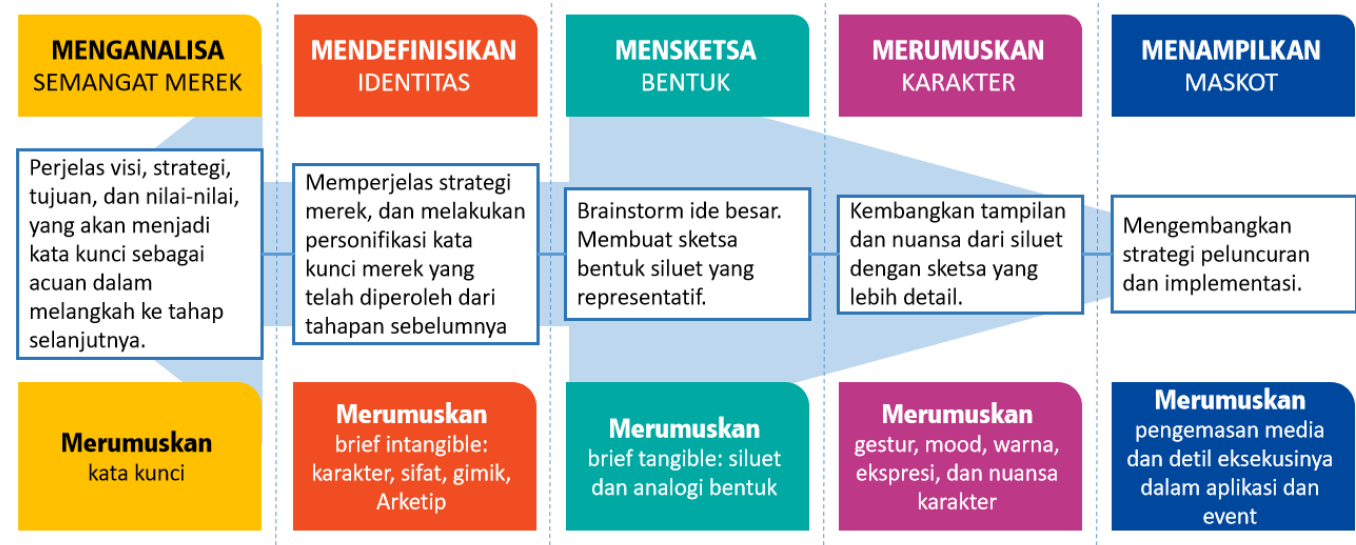

Gambar 7. Rumusan metode $5 \mathrm{M}$ pada tahapan perancangan maskot

[Sumber: Armayuda, 2020]

\subsection{Contoh aplikasi perancangan desain maskot dengan metode desain adaptif}

Untuk memberikan gambaran aplikatif dari model perancangan maskot di atas dapat diihat contoh aplikasinya dengan menggunakan karakter populer Sonic untuk memudahkan proses pemahaman:

1. Merumuskan kata kunci: Ambil satu contoh setelah mempelajari visi, misi, strategi, merek/perusahaan terkait dapat diambil kata kunci, cepat, humble, dinamis, dan semangat muda yang akan menjadi acuan brief implementasi tahapan selanjutnya. Secara singkat tahapan ini dapat dipahami dengan instruksi singkat "merumuskan pesan/ide/konsep merek/perusahaan ke dalam beberapa kata kunci utama". 
2. Merumuskan brief karakter: Tahap ini dilakukan dengan cara memperjelas kata kunci ke dalam ranah visual dengan simbol-simbol yang relevan yang akan membantu dalam tahapan selanjutnya seperti cepat bisa direpresentasikan dengan kilat, humble diasosiasikan dengan senyuman, dan semangat muda dengan api biru. Secara sederhana tahapan ini juga bisa disederhanakan dengan instruksi "merumuskan sifat merek/perusahaan ke dalam brief kata kunci yang bisa disimbolkan" tahapan ini merupakan tahapan transisi dari verbal kata kunci ke dalam ranah visual.

3. Merumuskan bentuk: Tahap ini merumuskan simbol ke dalam bentuk filosofis yang dapat diaplikasikan, misalkan dari makna sejarah atau filosofi merek terdapat kaitan dengan hewan tertentu (kita ambil contoh landak) maka itu akan menjadi satu alernatif bentuk yang akan menjadi acuan dalam mendesain siluet karakter maskot. Instruksi sederhana pada tahap ini adalah "mentransformasi simbol ke dalam bentuk siluet". Dalam konteks ini bentuk tersebut diharapkan menjadi outline transformasi simbol yang merupakan hasil akhir dari pemahaman makna filosofis sebuah merek/perusahaan.

4. Merumuskan nuansa karakter: Merupakan tahap di mana bentuk siluet yang telah disepakati diolah kedalam draft sketsa yang lebih detail dengan menambahkan atribut warna, gestur (bagaimana ia berdiri berjalan dan bertingkah tentunya yang tetap mempresentasikan citra merek di awal). Pada tahap ini karakter maskot secara visual telah bisa dilihat dan selesai namun untuk menghindari penyalah gunaan maskot yang bisa mnghancurkan citra merek maka tahap selanjutnya menjadi penting. Instruksi sederhana dalam tahap ini adalah "men-detailkan karakter bentuk dengan gestur dan ekspresi tampilan".

5. Merumuskan panduan implementasi: pada tahap ini desainer hendaknya membuat sebuah panduan dalam penggunaan maskot. Sebagaimana standar panduan dalam merancang logo, maskot juga harus memiliki acuan penggunaanya agar tidak merusak citra merek dalam mimplementasinya. "Merumuskan panduan implementasi penggunaan maskot" adalah instruksi sederhana yang bisa disimpulkan dari tahap ini.

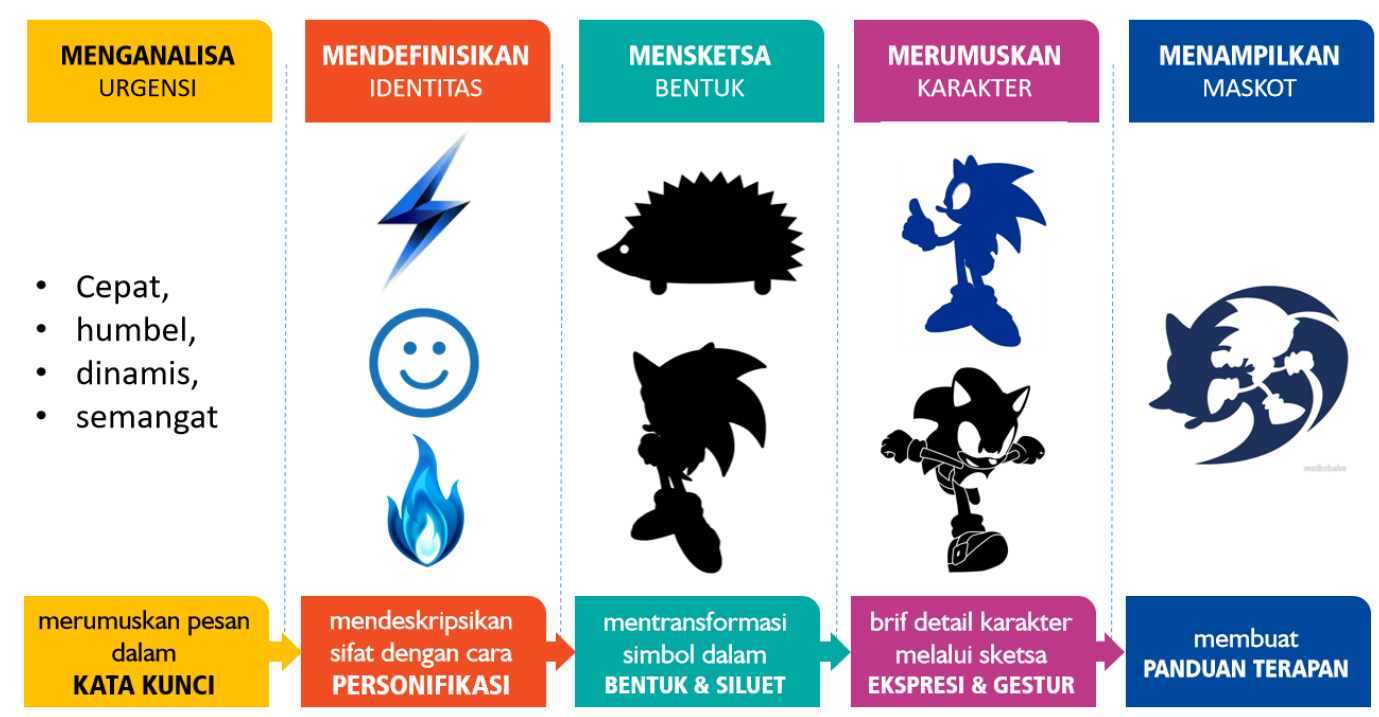

Gambar 8. Contoh simulasi implementasi metode 5M menggunakan analogi karakter Sonic

[Sumber: Armayuda, 2020] 


\section{KESIMPULAN}

Dari penjabaran tulisan ini dapat dirumuskan bahwa berdasarkan teori Norman (2002) terkait tiga level dalam sebuah desain, visceral, behavioral, dan reflective, maskot merupakan salah satu bagian dalam desain dan pemasaran khususnya pada level reflective. Melalui komparasi dari bagan Hsu, Lin, dan Chu (2004), dirumuskan bahwa logo mewakili level outter, brand pada level middle, dan maskot pada level inner. Hal tersebut dikarenakan maskot bisa menjadi sebuah perwujudan citra dari sebuah karakteristik merek tertentu yang bisa langsung memberikan kedekatan emosi pada pelanggan. Demikian juga dapat disimpulkan, jika sebuah logo adalah wajah dari sebuah merek/perusahaan, dan merek/brand adalah sebuah badan, maka maskot dapat menjadi sebuah tangan yang bisa langsung menjabar pelanggan.

Kesimpulan berikutnya adalah Alina Wheeler telah memformulasikan tahapan atau langkah dalam membangun sebuah merek/brand ke dalam lima tahapan merancang maskot dengan formulasi: 1) Merumuskan urgensi dankata kunci, 2) Merumuskan brief karakter yang tak terlihat 3) Merumuskan brief yang terlihat sebatas bentuk siluet maupun analogi bentuk, 4) Merumuskan gestur, mood, warna, ekspresi tampilan, dan nuansa karakter di dalam siluet pada tahap sebelumnya, 5) Merumuskan pengemasan media dan aturan baku mengenai peng-implementasianya. Proses adaptasi tersebut didasarkan pada perumusan teknis tahapan perancangan brand yang hanya menyentuh aspek visual dengan relevansinya pada perancangan sebuah maskot.

Dari dua kesimpulan tersebut disarankan agar setiap desainer yang merancang maskot hendaknya juga mempertimbangkan aspek di luar proses desain untuk mendapatkan dampak yang lebih baik. Aspek eksternal tersebut di antaranya adalah pertimbangan nilai moral dan spiritual. Maksudnya adalah dalam konteks budaya timur maskot yang terlalu mengeksploitasi sosok yang sensual dan erotis akan menjadi gagasan yang kontra produktif dengan kultur normatif yang ada. Begitu juga yang dimaksud dalam aspek spiritual adalah dalam ajaran agama Islam khususnya penggambaran makhluk bernyawa menjadi kontroversi, untuk itu kami menghimbau agar menghindari penggambaran mata dan wajah sebagaimana yang telah umum menjadi solusi dalam penampilan gambar dalam konteks tertentu. Ketika desain cenderung mengejar tren perasaan pengguna, kesadaran akan tanggung jawab desainer ditantang, itu karena tidak semua pengguna memiliki kesadaran akan efek kepuasan mereka sendiri (Armayuda, Kurniawan, Lin, 2018).

\section{DAFTAR PUSTAKA}

Armayuda, E. (2016): Pendekatan Gaya Visual Topeng Malangan Sebagai Adaptasi Dalam Perancangan Karakter Virtual, Jurnal Desain, 3(3), 175-188.

Armayuda, E. Kurniawan, O., Lin, R. (2018). Book of proceedings of the $7^{\text {th }}$ International Ergonomics Conference - Ergonomics 33-42, Zadar, Croatia

Armayuda, E., (2019). Journal of Arts and Humanitites. Vol.08, 57-74

Hsu, C. H, Lin, R.T., \& Chiu W. K. (2004). Taiwanese aboriginal product design. International Innovation Design Symposium Thesis, 157-164. 
Kochhar, D., \& Singh, P.P., (2019). International Journal of Recent Technology and Engineering (IJRTE), Vol7, 265-268

Komninos, A. (2020). Norman's Three Levels of Design. Retrieved July 20, 2020, from https://www.interaction-design.org/literature/article/norman-s-three-levelsof-design

Mohanty, S.S., (2014), IJCEM International Journal of Computational Engineering \& Management, Vol. 17, 42-44

Norman, D. A. (2002). The design of everyday things. New York: Basic Books

Rustan, S., (2009). Mendesain Logo. PT. Gramedia Pustaka Utama.

Roger, S. (2010). Level Up. United Kingdom, Chicester: Wiley.

Tubik Studio, (2019). The Power of Mascots in Branding and UI Design, [online] Available at: $\quad<$ https://uxplanet.org/the-power-of-mascots-in-branding-and-ui-design5973d12be955> [Accessed 17 March 2020]

Wheeler, A. (2009), Designing Brand Identity, John Wiley \& Sons, Inc., Hoboken, New Jersey

Yadav, P., (2017). A Study of Young Consumer' Perception on Mascout Design Characteristic with Reference to Indian Food Brand. a thesis: Department of design Indian Institute of Technology Guwahati, Assam, India

Sumber Gambar

Api biru : shorturl.at/stF05

Smile biru : shorturl.at/pwPRW

Kilat biru : shorturl.at/hyHQZ

sonic siluet biru: shorturl.at/iuzD1

Siluet landak : shorturl.at/agiK9

sonic siluet : shorturl.at/wCSU0

sonic siluet aksi: shorturl.at/uwFS8

sonic simbol : shorturl.at/dptwA 